\title{
Outcome of Pulpotomy Using Bioceramic Material in Mature Permanent Anterior Teeth with Traumatic Pulp Exposure: A Case Report
}

\author{
Rugma Raj ${ }^{1}$, Mali G Nair ${ }^{2}$, Shiji Dinakaran ${ }^{3}$, Anulekh Babu ${ }^{4}$, Shabna Shajahan ${ }^{5}$, Kanchana Devi ${ }^{6}$, Swathi P Devadas ${ }^{7}$, Parvathy \\ D Kumar ${ }^{8}$, Amitha Palliyali ${ }^{9}$
}

\begin{abstract}
Aim: To evaluate the outcome of pulpotomy in traumatized mature permanent teeth using bioceramic material.

Rationale: To preserve the vitality of the tooth

Background and objectives: Traumatic injuries to anterior permanent teeth are more common in which complicated crown fracture needs special attention. Preservation of pulp vitality is important rather than replacing it with a root filling material following pulp exposure. This case report evaluates the treatment outcome following pulpotomy using bioceramic materials in traumatized mature permanent anterior teeth based on clinical evaluation at 3,6,12 months follow-up and radiographic evaluation at 12 months or any time during the follow-up period if symptomatic. Clinically visible coronal discoloration and diffuse calcification were also assessed.

Case description: A 14-year-old male patient was reported at the department following road traffic accident (RTA). On examination, a complicated crown fracture of teeth \#9 was noted. Partial pulpotomy was performed. Pulpotomy medicament used was Biodentin. Nearly, $2.5 \%$ sodium hypochlorite used for hemostasis. The permanent restoration given was composite. Follow-up intervals were 3, 6, and 12 months.

Conclusion: Pulpotomy is a suitable alternative to root canal treatment in traumatized anterior teeth with pulp exposure. Biodentin is a suitable bioceramic material for pulpotomy which promotes dentin bridge formation and protects the vitality of the remaining portions of the pulp. Further research and clinical trials are also needed to develop a treatment protocol.

Clinical significance: Preservation of vitality of teeth has paramount importance as the vital pulp nourishes dentin and also forms reparative dentin in response to stimuli.

Keywords: Biodentin, Complicated crown fracture, Dental trauma, Pulpotomy.

Journal of Operative Dentistry and Endodontics (2021): 10.5005/jp-journals-10047-0111
\end{abstract}

\section{INTRODUCTION}

Traumatic dental injuries occur frequently in children and young adults, comprising $5 \%$ of all injuries. Twenty-five percent of all schoolchildren experience dental trauma and about $33 \%$ of adults experience trauma to the permanent dentition. ${ }^{1}$

In preschool children (0.6 years), these injuries mainly result from falling during the daytime in the home environment. In schoolchildren (7-15 years), the injury mainly results from being pushed and hit, and from falling; these occur mainly in school or sports areas during the daytime. ${ }^{2}$

Vital pulp tissue has the inherent capacity to produce reparative dentin in response to biological and pathological stimuli.

Vital pulp therapy (VPT) aims to preserve and maintain pulp tissue. $^{3,4}$ In the absence of microbial contamination pulp tissue has the innate capacity for repair indicates that preservation of the pulpally involved permanent tooth through VPT is a treatment alternative. $^{5}$

A biocompatible material that can not only initiate healing and repair but also shield the pulp from further insult is placed over it. Various materials have been tried as pulpotomy medicament giving successful to detrimental results. Now, bioceramic materials have become recognized as the gold-standard material for pulpotomy.

This case report evaluates the treatment outcome following pulpotomy using bioceramic materials in traumatized mature

\begin{abstract}
${ }^{1-9}$ Department of Conservative Dentistry and Endodontics, Government Dental College, Thiruvananthapuram, Kerala, India
\end{abstract}

Corresponding Author: Rugma Raj, Department of Conservative Dentistry and Endodontics, Government Dental College, Thiruvananthapuram, Kerala, India, Phone: +91 9048366148, e-mail: rukku.pvr@gmail.com

How to cite this article: Raj R, Nair MG, Dinakaran S, et al. Outcome of Pulpotomy Using Bioceramic Material in Mature Permanent Anterior Teeth with Traumatic Pulp Exposure: A Case Report. J Oper Dent Endod 2021;6(1):24-27.

Source of support: Nil

Conflict of interest: None

permanent anterior teeth based on clinical evaluation at 3, 6, 12 months follow-up and radiographic evaluation at 12 months or any time during the follow-up period if symptomatic. Clinically visible coronal discoloration and diffuse calcification were also assessed.

\section{Case Description}

A 14-year-old male patient was reported at the department following RTA. On examination, a complicated crown fracture

() The Author(s). 2021 Open Access This article is distributed under the terms of the Creative Commons Attribution 4.0 International License (https://creativecommons. org/licenses/by-nc/4.0/), which permits unrestricted use, distribution, and non-commercial reproduction in any medium, provided you give appropriate credit to the original author(s) and the source, provide a link to the Creative Commons license, and indicate if changes were made. The Creative Commons Public Domain Dedication waiver (http://creativecommons.org/publicdomain/zero/1.0/) applies to the data made available in this article, unless otherwise stated. 
of teeth \#9 was noted (Fig. 1). The patient reported 3 days after the injury and his medical history was noncontributory. Positive response to pulp sensibility tests (electric pulp tester [EPT] and cold test) were noted. No clinical signs or symptoms of swelling, tooth mobility, and tooth displacement.

\section{Pulpotomy Treatment Protocol}

After the administration of local anesthesia (lignocaine hydrochloride $2 \%$ with adrenaline 1:100,000), rubber dam application was done, and the crown was disinfected with $5 \%$ sodium hypochlorite (Fig. 2). The roof of the pulp chamber was removed by using a coarse, high-speed diamond bur. After pulp exposure, the cavity was flushed with $2.5 \%$ sodium hypochlorite. Partial removal of pulp was done. Hemostasis was achieved by the application of a cotton pellet moistened with $2.5 \%$ sodium hypochlorite for up to a maximum of 10 minutes (Fig. 3). Biodentin was mixed and placed over the exposed pulpal tissue (Fig.4). Then a layer of resin-modified glass ionomer (RMGIC) was placed over the material and light-cured for 20 seconds. Finally, a composite restoration was given over the RMGIC. Maxillary and mandibular impressions were taken for wax buildup. Polyvinyl siloxane putty index was made (Fig. 5) and composite buildup was done (Fig. 6).

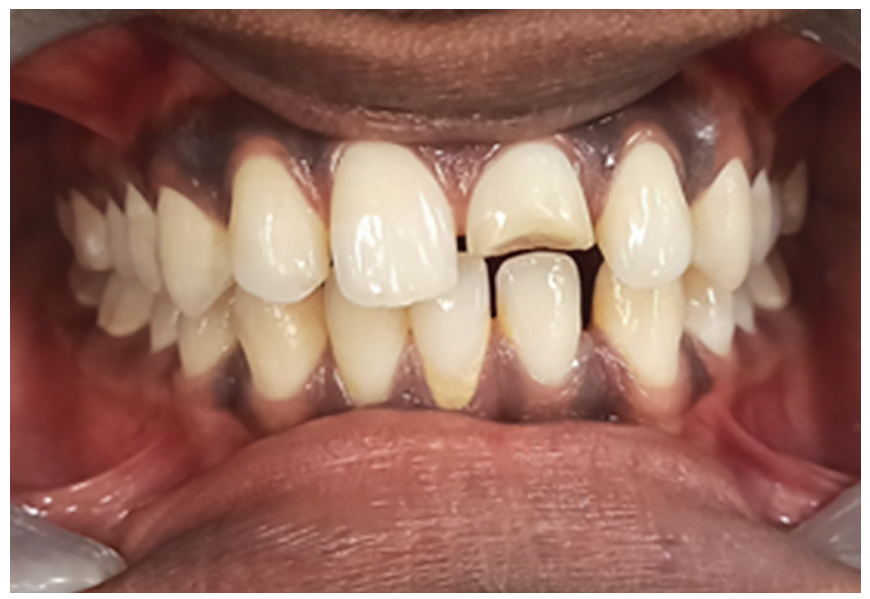

Fig. 1: Preoperative photograph

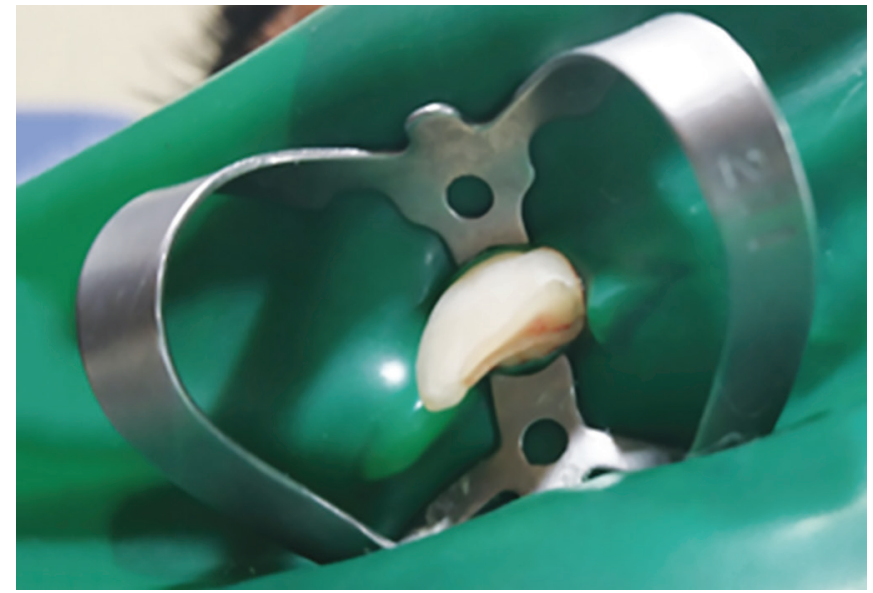

Fig. 2: Rubberdam placement

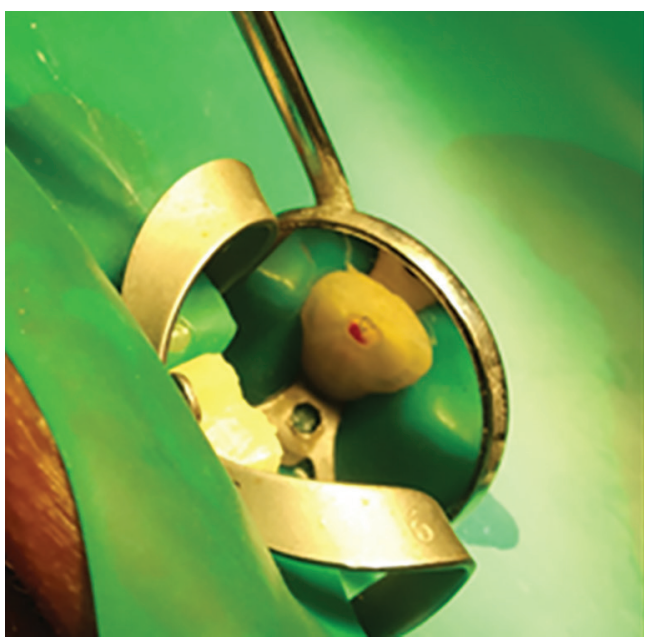

Fig. 3: Hemostasis achieved

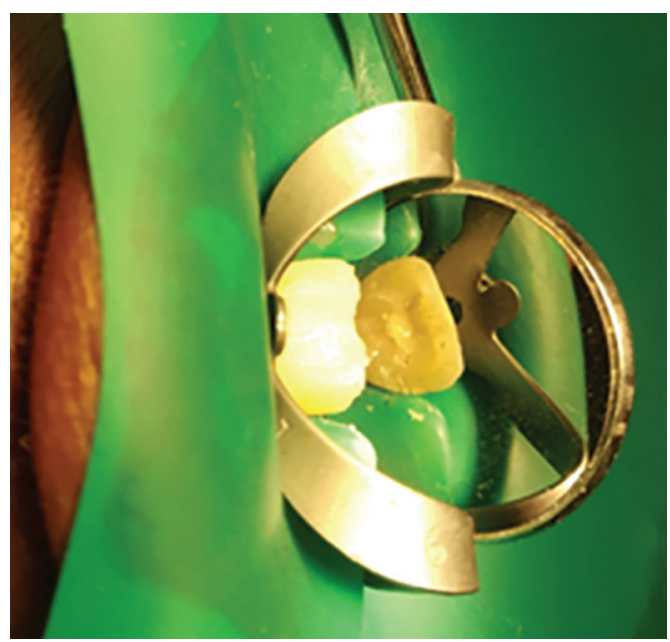

Fig. 4: Biodentin placement

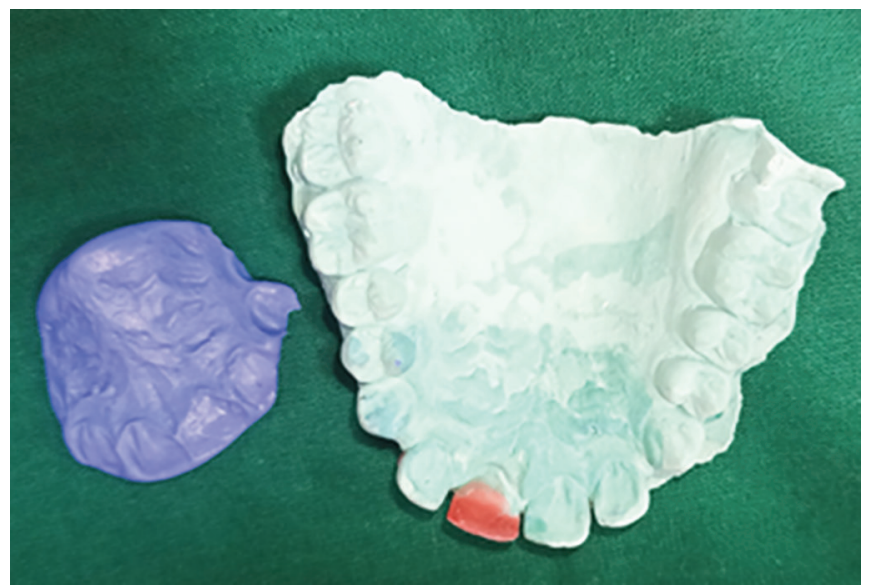

Fig. 5: Polyvinyl siloxane impression 


\section{Assessment of Treatment Outcome}

Evaluation of treatment outcome will be based on clinical and radiographic examination.

\section{Clinical Criteria}

- Absence of spontaneous pain or discomfort.

- No tenderness to palpation and percussion.

- Soft tissue around the teeth is normal with no swelling or sinus tract.

\section{Radiographic Criteria}

No root resorption or new periapical pathosis.

\section{Outcome Measures}

\section{Success}

Asymptomatic without radiographic signs of periapical pathology, followed up over a period of 12 months will be considered successful.

\section{Failure}

A tooth that became symptomatic with or without radiographic signs of periapical pathology, root resorption, or asymptomatic with radiographic signs of periapical pathology followed up over a period of 12 months will be considered as failure.

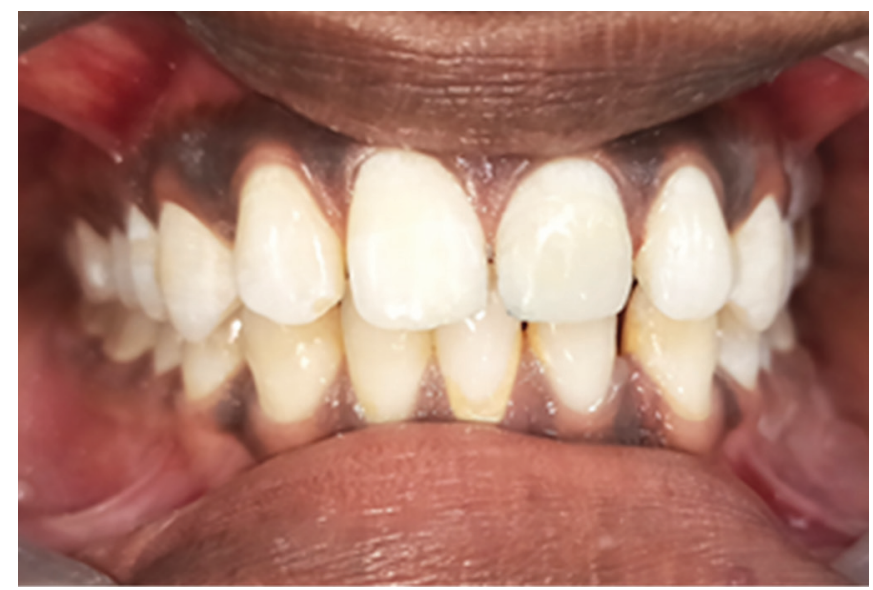

Fig. 6: Postoperative photograph
Other variables to be measured are:

- Radiographically visible dentin bridge formation

- Diffuse calcification of root canal

During the follow-up period, the tooth was asymptomatic and gave a positive response to pulp sensibility tests. At 12 month follow-up, dentin bridge formation and diffuse calcification were noted and no signs of periapical pathology in the radiograph (Fig. 7).

\section{Discussion}

Proper diagnosis, treatment planning, and follow-up are important for achieving a favorable outcome. ${ }^{6}$ Trauma to the tooth is followed by pulpal hyperemia, alteration in the blood flow in the pulp, and over time can cause pulpal necrosis.?

The incidence of complicated crown fractures ranges from 2 to $13 \%$ of all dental injuries. ${ }^{8}$ Nagarajappa et al. found that maxillary central incisors were the most frequently affected teeth (83.7\%), followed by maxillary lateral incisors (14.9\%) and mandibular central incisors (1.4\%). ${ }^{9}$ A Ramachandran et al. found that tooth \#9 (38.5\%) followed by \#8 (33.9\%) was commonly affected. ${ }^{10}$

It was observed that pulpotomy offered a viable alternative to root canal treatment for teeth with vital pulps in the short term. However, there is insufficient clinical evidence to consider this technique for the treatment of every permanent tooth. ${ }^{11}$

In a study, both MTA and biodentin (BD) showed similar clinical and radiographic outcomes when used as pulpotomy materials in the treatment of traumatized immature anterior permanent teeth. ${ }^{12}$

Biodentin is a suitable material for pulpotomies on anterior permanent teeth with complicated crown fractures. It does not cause significant discoloration and it allows root maturation. ${ }^{13}$

The interval between trauma and treatment is not critical for pulp recovery provided that the pulp is vital, the superficially inflamed tissue is removed, and a proper aseptic procedure is performed using biocompatible materials. ${ }^{14}$

Biodentin has been proven to be biocompatible (it does not damage pulpal cells in vitro or in vivo). It has the capability of stimulating tertiary dentin formation. ${ }^{15}$

It was shown that when BD was applied directly onto the pulp, it induced an early form of reparative dentin synthesis, probably due to modulation of pulp cell transforming growth factor-beta 1 secretion. $^{16}$

After pulpotomy, the response threshold to EPT was higher in comparison to the before EPT readouts. Increasing the response
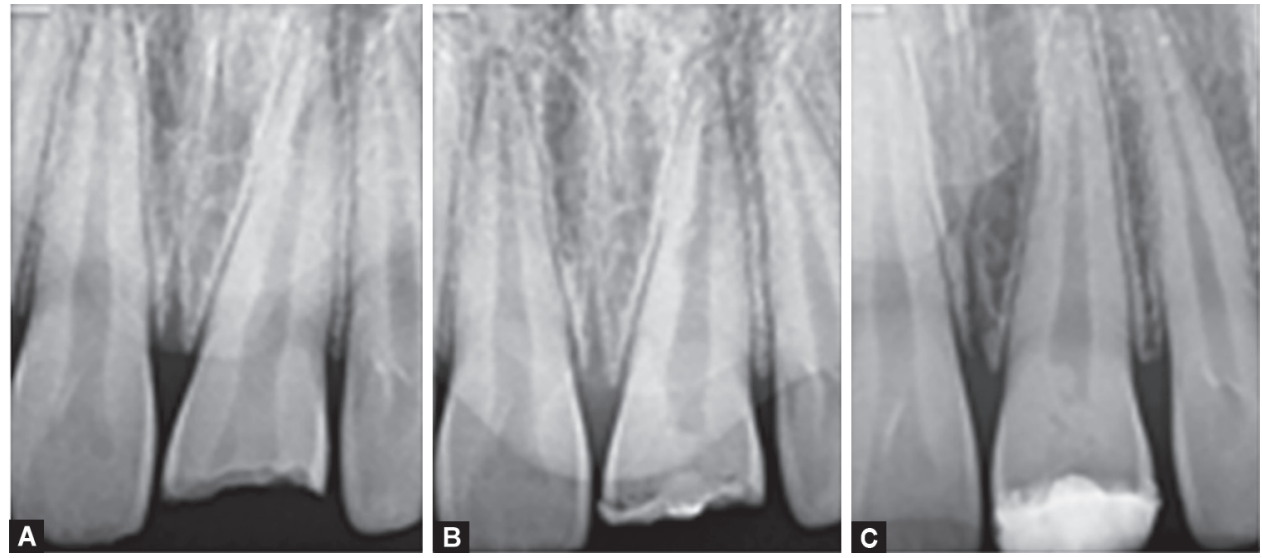

Figs 7A to C: Preoperative, postoperative, follow-up radiographs 
threshold after pulpotomy may be a consequence of removing the rich nerve supply in the coronal pulp chamber. Electric pulp tester is a useful method particularly in teeth that have limited fluid flow through dentinal tubules, such as with dentin sclerosis or in pulpotomized teeth. ${ }^{17}$

\section{Conclusion}

On the basis of observations made from this study, it can be concluded that pulpotomy is a suitable alternative to root canal treatment in traumatized anterior teeth with pulp exposure even if performed several days after pulp exposure. Biodentin is a suitable bioceramic material for pulpotomy which promotes dentin bridge formation and protects the vitality of the remaining portions of the pulp. Further research and clinical trials are also needed to develop treatment protocols to maximize clinical success.

\section{References}

1. Levin L, Day PF, Hicks L, et al. International Association of Dental Traumatology guidelines for the management of traumatic dental injuries: general introduction. Dent Traumatol 2020;36(4):309-313. DOI: 10.1111/edt.12574.

2. Crona-Larsson G, Norén JG. Luxation injuries to permanent teeth - a retrospective study of etiological factors. Dent Traumatol 1989;5(4):176-179. DOI: 10.1111/j.1600-9657.1989.tb00355.x.

3. Ward J. Vital pulp therapy in cariously exposed permanent teeth and its limitations. Aust Endod J 2002;28(1):29-37. DOI: 10.1111/ j.1747-4477.2002.tb00364.x.

4. Cvek M. A clinical report on partial pulpotomy and capping with calcium hydroxide in permanent incisors with complicated crown fracture. J Endod 1978;4(8):232-237. DOI: 10.1016/ S0099-2399(78)80153-8.

5. Seltzer S, Bender IB, Ziontz M. The dynamics of pulp inflammation: correlations between diagnostic data and actual histologic findings in the pulp. Oral Surg Oral Med Oral Pathol 1963;16:969-977. DOI: 10.1016/0030-4220(63)90201-9.
6. Bourguignon C, Cohenca N, Lauridsen E, et al. International Association of Dental Traumatology guidelines for the management of traumatic dental injuries: 1. Fractures and luxations. Dent Traumatol 2020;36(4):314-330. DOI: 10.1111/edt.12578.

7. Padawe $D$, Takate V, Dighe K, et al. Prevalence of traumatic injuries to anterior teeth in 9-14 year school-going children in Mumbai, India. J Contemp Dent Pract 2019;20(5):622-630. PMID: 31316029.

8. Aggarwal V, Logani A, Shah N. Complicated crown fractures management and treatment options. Int Endod J 2009;42(8):740-753. DOI: 10.1111/j.1365-2591.2009.01588.x.

9. Nagarajappa R, Ramesh G, Uthappa R, et al. Risk factors and patterns of traumatic dental injuries among Indian adolescents. J Dent Sci 2020;15(1):96-103. DOI: 10.1016/ j.jds.2019.07.003.

10. Ramachandran A, Khan SIR, Baskaradoss J. Epidemiology of traumatic dental injuries among adults in an Indian sub-population. 2019 [In review].

11. Simon S, Perard M, Zanini M, et al. Should pulp chamber pulpotomy be seen as a permanent treatment? Some preliminary thoughts. Int Endod J 2013;46(1):79-87. DOI: 10.1111/j.1365-2591.2012.02113.x.

12. Abuelniel GM, Duggal MS, Kabel N. A comparison of MTA and Biodentin as medicaments for pulpotomy in traumatized anterior immature permanent teeth: a randomized clinical trial. Dent Traumatol 2020;36(4):400-410. DOI: 10.1111/edt.12553.

13. Borkar S, Ataide I. Biodentin pulpotomy several days after pulp exposure: four case reports. J Conserv Dent 2015;18(1):73. DOI: 10.4103/0972-0707.148901.

14. Haikal L, Ferraz dos Santos B, Vu D-D, et al. Biodentin pulpotomies on permanent traumatized teeth with complicated crown fractures. J Endod 2020;46(9):1204-1209. DOI: 10.1016/j.joen.2020.06.003.

15. Bhat $S$, Hegde $S$, Adhikari F, et al. Direct pulp capping in an immature incisor using a new bioactive material. Contemp Clin Dent 2014;5(3):393. DOI: 10.4103/0976-237X.137967.

16. Laurent $P$, Camps J, About I. Biodentin ${ }^{T M}$ induces TGF- $\beta 1$ release from human pulp cells and early dental pulp mineralization: biodentin induces mineralisation and TGF- $\beta 1$ release. Int Endod J 2012;45(5):439-448. DOI: 10.1111/j.1365-2591.2011.01995.x.

17. Kazemipoor M, Mahmoodi S. Evaluation of the response to electric pulp testing before and after pulp chamber pulpotomy. Int J Clin Dent 2018;11(2):109-115. 